\title{
Isolation of Nimbolide from Azadirachta Indica Assisted by Molecular Docking as an Antiproliferative Agent
}

\author{
Tribhuvan Singh ${ }^{1 *}$, Mihir Y Parmar ${ }^{2}, J_{\text {Dinesh Babu }}{ }^{1}$, Dinesh Pore ${ }^{2}$ and Sachin Kumar Sharma ${ }^{3}$ \\ ${ }^{1}$ Scient Institute of Pharmacy, Jawaharlal Nehru Technological University, India
}

${ }^{2}$ Bharat Institute of Technology, Jawaharlal Nehru Technological University, India

${ }^{3}$ Parul Institute of Pharmacy and Research, Parul University, India

Submission: February 08, 2019; Published: March 25, 2019

*Corresponding author: Dr. Tribhuvan Singh, Professor, Pharmaceutical Analysis, Scient Institute of Pharmacy, Ibrahimpatnam, Jawaharlal Nehru Technological University, Hyderabad, Telangana, India

Abstract

The current study on Nimbolide was performed to identify its Antiproliferative Property Nimbolide from kernels of Azadirachta indica gathered from Ranga Reddy-Dist, was separated dried and changed into coarse powder. The seed was defatted and massed utilizing methanol in soxhlet Apparatus. The methanolic extract acquired from seeds is analyzed under High Performance/pressure Liquid Chromatography by Reverse phase technique for confinement of Nimbolide by Docking of Nimbolide through Molecular Operating Environment programming. This proclaimed Nimbolide has capacity of binding $12.3 \%$ to a Glycine 131 experiencing polar associations. Nimbolide interact with Cyclin E, was reclaimed from the Protein Data Bank. Demonstrating that Nimbolide has an agreeable expanded life span (54.32 and 65.16 ), diminished the viable cells (52.3 \pm 1.5 and $32.5 \pm 1.3)$, and volume of tumor $(3.2 \pm 0.03$ and $2.4 \pm 0.04)$.

Keywords: Azadirachta Indica; Cervical cancer; Molecular docking; Nimbolide; 5-Fluorouracil (HeLa) cell line

\section{Introduction}

The Cancer is defined as abnormal and repetitive growth of the cell on various region of the body, Chemotherapy is a much of the time utilized treatment for cancer which include medicines (drugs) like carboplatin, 5-fluorouracil, paclitaxel, cisplatin, topotecan, cyclophosphamide, irinitecan, gemcitabine, docetaxel, doxorubicin and mitomycin. The above Drugs have certain toxicities such as Nephrotoxicity, Hepatotoxicity, Anemia, Thrombocytopenia, Leucopenia, Degeneration of hair follicle etc, Because of the low therapeutic index, the drugs degenerate normal cells with cancerous cells, Thus it is necessary to develop the medication and therapy to reduce this cytotoxic effects, This can be achieve by using natural and safe agents for the treatment of cancer. In this point of view some phytochemical constituents were recognized, for example, taxol, vincristine, and vinblastine [1-2]. There is expanding number of distributions on Azadirachta indica and its concentrate to battle against various tumors. Azadirachta indica is evergreen, tropical, having angled molded green leaves and trunk of timber with bug repellent properties. Generally, Azadirachta indica demonstrated an anticancer movement by advancing the cell reinforcement chemical, and adjusting the intracellular segments fundamental for tumor development and advancement, for example, Cyclin D, Cyclin B,
Cyclin B1, Cyclin1, Cyclin E, P53, PCNA, P21,GST-P. Nimbolide was found to bind with the cell cycle energy in cancer cells by inhensing the cell cycle capture at G1/S or G2/M stage through concealment of Cyclin, CDKs and PCNA [3-6].

Nimbolide can be obtained from Azadirachta indica seeds powder by utilizing a suitable solvent, for example, ethyl acetate derivation for microwave-helped extraction, and it is refluxed for 15 hrs. 100 grams of Azadirachta indica kernels powder gives close around $1 \mathrm{gm}$ of Nimbolide. The Investigation of molecular docking was performed and gave a dream to the cooperating method of Nimbolide by utilizing Molecular Operating Environment (MOE) 2008 programming. Recently research found that Nimbolide has capacity of binding $12.3 \%$ to a Glycine 131 with polar communications. Nimbolide was known to interact with Cyclin E, which causes phosphorylation of cancer cell and stop the G1/S stage protein expression [7].

\section{Materials and Methods}

\section{Extraction of nimbolide from seeds of azadirachta indica}

Nimbolide encases 55-60\% active ingredient. The Azadirachta indica seeds were acquired from neighborhood, nimbolide were 
detached from them. The seeds were dried and made into coarse powder. The Azadirachta indica portions were defatted utilizing a solvent such as, ethyl acetic acid in a microwave (Make: Samsung, Demonstrate: 2015) by the extraction technique. By utilizing soxhlet, the methanolic concentrate was readied (Make: Nsaw, Demonstrate: 2016) refluxed for 15 hrs, i.e hot extraction methodology and dissolvable recuperation done by utilizing turning evaporator, (Make: Aditya, Display: 2015) then the concentrate was disengaged by a current strategy i.e. coordinate utilization of methanolic concentrate of parts of Azadirachta indica in a preparative invert stage HPLC without utilizing column chromatography, (Make: Sigmaaldrich, Show: 2016) to disengage Nimbolid [8].

\section{Studies which relates to molecular docking}

By utilizing MOE 2008 docking was finished. Cyclin E was acquired from PDB and receptor was imagined by succession alternative and cancellation of cofactors is made. Fractional protein charge was balanced utilizing power field technique and working of Helped Model (Golden 99) was balanced utilizing vitality refinement. 3D protonation was done at cut off 12.0 and hydrogen was included utilizing standard geometry $0.01 \mathrm{KJ}$ mole slopes Merck Sub-atomic Constrain Field (MMFF94x) was found after minimization. With the help of designer module the ligand structures were confined and with the methodology for Hamilton MMFF94 oblige field partial charges were adjusted and along these lines as showed by standard geometry 3D protonation and hydrogen were incorporated. At $0.01 \mathrm{KJ}$ mole slant of drive field MMFF94x imperativeness was limited to ligands at cut off 12. By using the decision reenactment docking was performed and it was trailed by dock on the dynamic areas of picked amino acids with the help of plan option and definitely the settings decisions, for instance, receptor and dissolvable, picked stores, drive field refinement, alpha triangle and best 30 speak to the docking was done. From the 30 best posed of each structure of compound in the wake of getting the results the satisfaction of best will be secure. In the course of action the best position of resultant score qualities were used for docking examination and cooperation [9].

\section{Protein data bank, nimbolide of molecular docking (PDB Code: 1W98)}

Activity of anticancer: Institutional Animal ethics committee of Guru Nanak Institute of Pharmacy, Hyderabad, India (Reg no: 1374/air conditioning/10/CPCSEA led a test convention on mice for the pharmacological screening (Figures $1 \& 2$ ). led a test convention on mice for the pharmacological screening. The screening of anticancer action was led on Male Albino Swiss which weighs up to 20-25 g. Under the conditions of standard lab, Male Albino Swiss was stayed aware of access to water and sustenance not essential. Going before in vivo test for the season of seven days the animals in condition of research office were allowed to modify. The creatures which were picked apportioned into 5 sets containing 12 animals each. From the supporter mice HeLa cell lines got and were suspended in a $0.9 \%$ Nacl average saline.

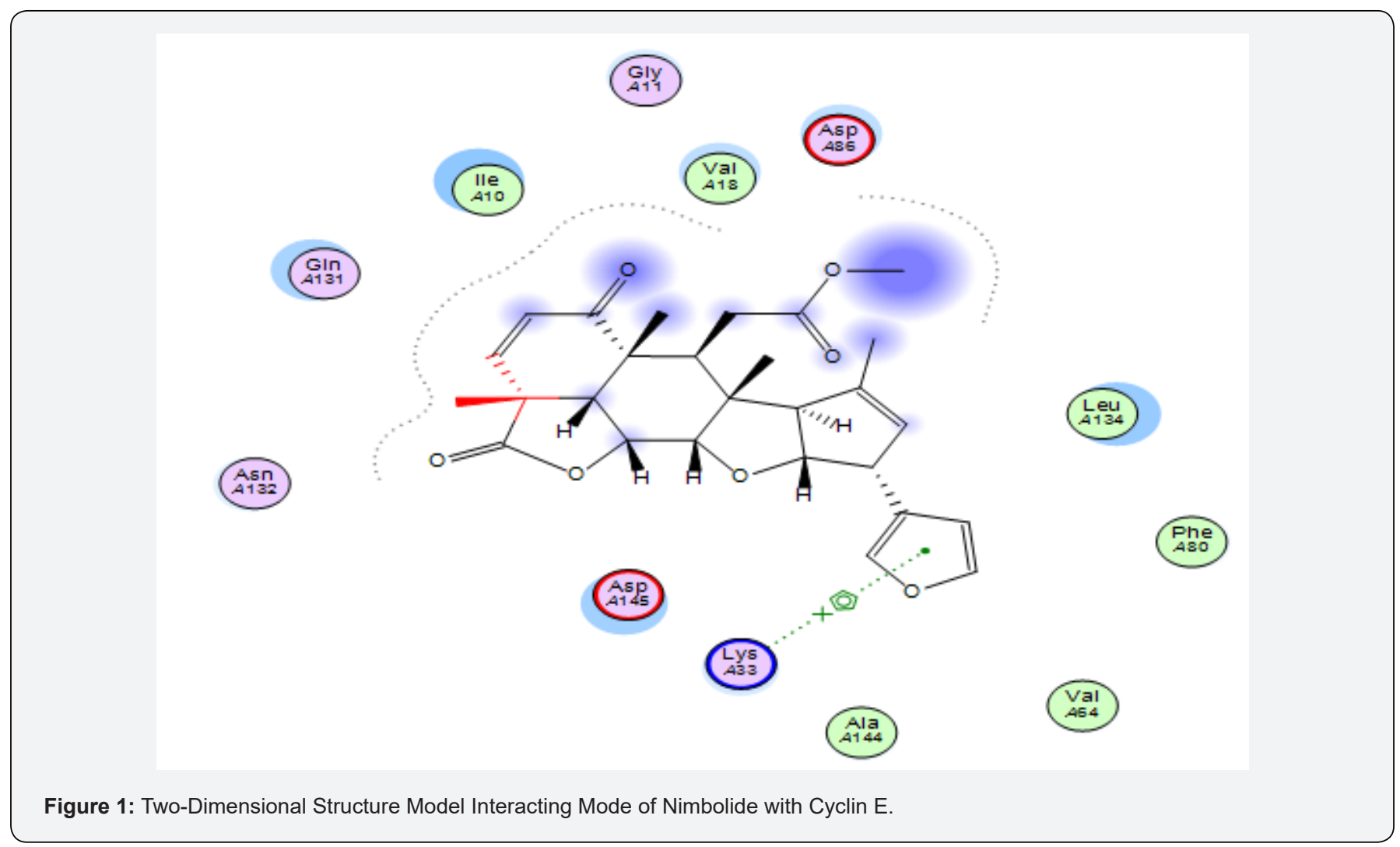




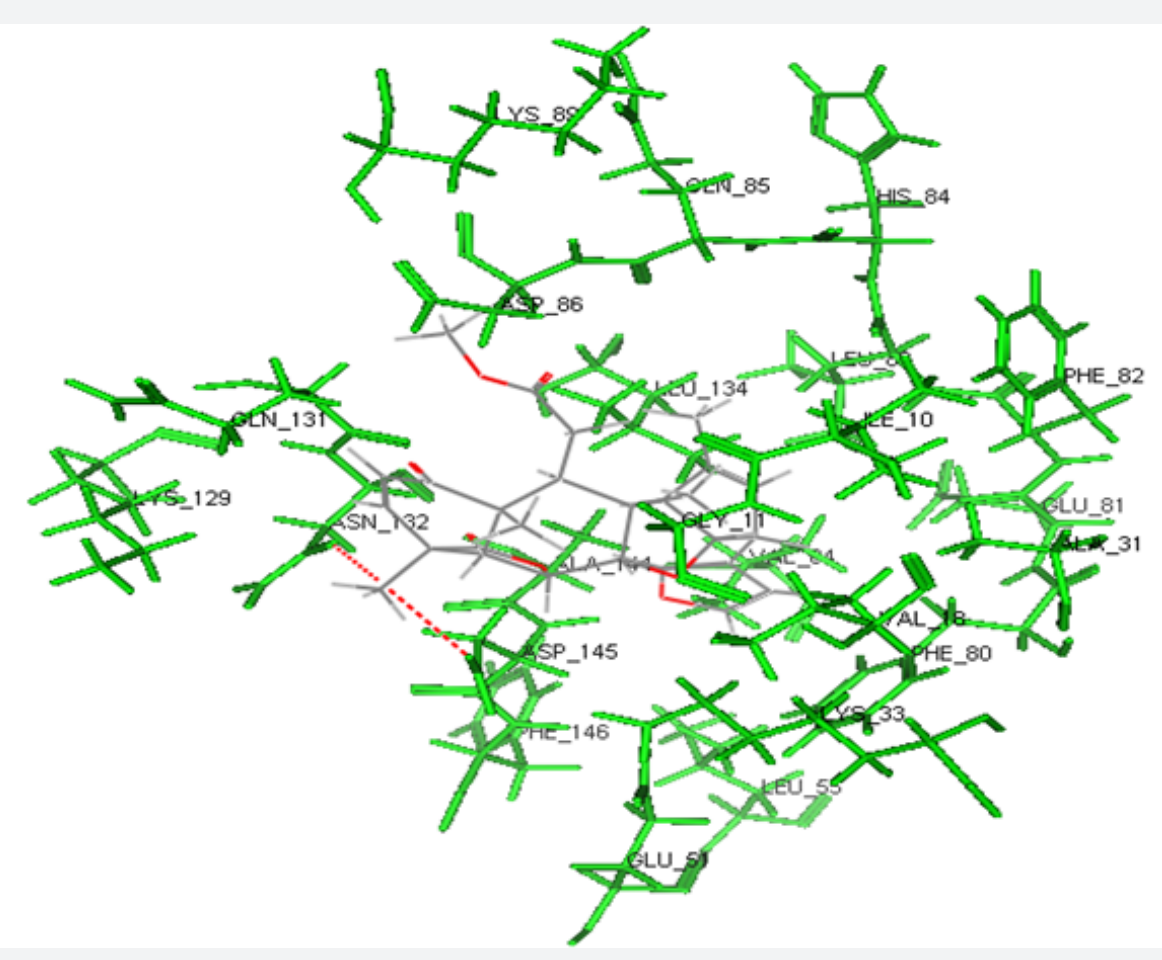

Figure 2: Three-Dimensional Structure Model Interacting Mode of Nimabolide with Cyclin E.

The check of cell was changed as per $2 \times 106$ cells $/ \mathrm{mL}$. Through the intraperitoneal course HeLa cell line were managed in all gathering from the ordinary gathering which is in control of day zero. Standard saline ( $5 \mathrm{~mL} / \mathrm{kg}$ body weight) is managed in social affair 1, HeLa cell line in get-together 2 and 5 -flourouracil ( $20 \mathrm{mg} / \mathrm{kg}$ body weight) in get-together 3 . At an estimation of 50 and $100 \mathrm{mg} / \mathrm{kg}$ body weight the compound test which has a place with get-together 4 \& 5 was controlled through intraperitoneal course. After tumor transplantation 5-flourouracil and the test compound were managed for 9 days. Each social affair of 6 creatures was yielded taking after 9 days. Against Cyclin E the evaluation of tumor was done. For the remaining each social affair of 6 mice were recorded for Mean survival time [10,11] (Table 1).

Table 1: Groups for In Vivo Antiproliferative Activity of Nimbolide against (HeLa) Cell line.

\begin{tabular}{|c|c|c|c|c|c|}
\hline Groups & Saline & Cancer Cell Line & No. of Cancer Cells & Control (C)/Standard (S)/Test (T) & Dose (mg/kg/body wt) \\
\hline 1 & Normal saline & - & - & - & - \\
\hline 2 & - & HeLa & $2 \times 106$ cells & Control & - \\
\hline 3 & - & HeLa & $2 \times 106$ cells & 5 -Fluorouracil (S) & $20 \mathrm{mg} / \mathrm{kg}$ \\
\hline 4 & - & HeLa & $2 \times 106$ cells & Nimbolide (T) & $50 \mathrm{mg} / \mathrm{kg}$ \\
\hline 5 & - & HeLa & $2 \times 106$ cells & Nimbolide (T) & $100 \mathrm{mg} / \mathrm{kg}$ \\
\hline
\end{tabular}

\section{Cell count of tumor}

The 6 mice were accomplished for the procedure of dissection and from the peritoneal depression the harvestation of aggregate liquid were done. With the assistance of graduated rotator (centrifuge tube) the volume was measured and PCV is noted at $1000 \mathrm{rpm}$ for 5 minutes. Exclusion test was done by using trypan blue color dye to check feasible cells which were counted in Neubauers counting chamber $[12,13]$.

\section{Increase life span \% and mean survival time}

On tumor development the Nimbolide movement was assessed and mortality recording is done inside the perception time frame. By utilizing formula, the life expectancy in \% was computed [14-16].

Percentage ILS $=\frac{\text { MST of treated group }- \text { MST of control group }}{M S T \text { of control group }} \times 100$

Mean Survival Time $=\frac{\text { Survival time of each mice in a group in days }}{\text { Ther }}$ Total number of mice

\section{Results and Discussion}

The examination of docking test was done on windows 2007 using MOE 2008. From the protein information bank 
(PDB code: 1W98), the Cyclin E was recuperated, current audits revealed that Nimbolide has a preferring of $59.2 \%$ and $72 \%$ towards amino acids like Glycine 131 and Lysine 89 with polar interchanges. Nimbolide known to interface with Cyclin E and causes phosphorylation, restrains the protein articulation of G1/S. The test tests were kept as standard and Nimbolide (50 and $100 \mathrm{mg} / \mathrm{kg}$ body weight from the estimations of reducing in tumor cell check, \% ILS 5-fluorouracil (20 mg/kg body weight) and MST. The results were showed up in (Table2). The activity of antitumor of attempted Nimbolide on HeLa cell line in vivo considers depends on upon no. of doable cells and tumor volume. In cell number and tumor volume the Nimbolide significance appeared in diminishment when diverged from control. The Nimbolide showed acceptable \%ILS (54.32 and $65.16)$, diminished the sensible cells $(52.3 \pm 1.5$ and $32.5 \pm 1.3)$, and tumor volume $(3.2 \pm 0.03$ and $2.4 \pm 0.04)$ independently as differentiated and 5-Fluorouracil. The Nimbolide exhibited a brilliant joint effort in docking of iota and the cervical anticancer headings were given. The amino acids, for instance, Asp-A86, Ile-A10, Gly-A131, Asn-A132, Asp-A145 speak with Cyclin E at the dynamic site. Gly-A 131 with the authority Nimbolide has ability of restricting $12.3 \%$ to a Glycine 131 experiencing polar connections.

Table 2: In Vivo Antiproliferative Activity of Nimbolide against (HeLa) Cell line.

\begin{tabular}{|c|c|c|c|c|}
\hline Groups & Mean Survival Time (MST) \pm SE & Increase Life Span (ILS) (\%) & Tumor Volume (TV) (ml) & Viable Cells (VC) (\%) \\
\hline 1 & - & - & - & - \\
\hline 2 & $18.5 \pm 0.23$ & - & $3.4 \pm 0.2$ & $94.5 \pm 3.6$ \\
\hline 3 & $36.6 \pm 0.48$ & 97.83 & $0.9 \pm 0.02$ & $18.1 \pm 1.8$ \\
\hline 4 & $19.5 \pm 0.52$ & 54.32 & $3.2 \pm 0.03$ & $52.3 \pm 1.4$ \\
\hline 5 & $27.3+0.34$ & 65.16 & $2.4 \pm 0.04$ & $32.5 \pm 1.3$ \\
\hline
\end{tabular}

\section{Conclusion}

In the present study anticancer activity of Nimbolide was performed in vivo. Compared to standard drug 5-Fluorouracil the Nimbolide was found to have potent anticancer activity. Moreover, the Nimbolide demonstrated huge docking communication with Cyclin E, dynamic site utilizing windows 2002, MOE 2008 programming. Result demonstrated that Nimbolide may prompt to powerful cervical anticancer agent.

\section{Acknowledgement}

I, Dr. Tribhuvan Singh, thankful to Sardar G.S Kohli, Vice Chairman, Guru Nanak Institutions Technical Campus, Hyderabad, to carry out the research work for providing necessary facilities.

\section{References}

1. Salehzadesh A, Akhkha A, Cushley W, Adams RLP, Kusel JR, et al. (2003) The antimitotic effect of the neem terpenoid azadirachtin on cultured insect cells. Insect Biochem Mol Biol 33(7): 681-689.

2. Subapriya R, Nagini S (2005) Ethanolic neem leaf extract protects against N-methyl-N'-nitro-N-nitrosoguanidine-induced gastric carcinogenesis in Wistar rats. Asian Pac J Cancer Prev (4): 215-223.

3. Subapriya R, Kumaraguruparan R, Nagini S (2006) Expression of PCNA, cytokeratin, Bcl-2 and p53 during chemoprevention of hamster buccal pouch carcinogenesis by ethanolic neem (Azadirachta indica) leaf extract. Clin Biochem (39): 1080-1087.

4. Harish KG, Chandra Mohan KVP, Jagannadha RA, Nagini S (2009) Azadirachtin a limonoid from Azadirachta indica inhibits proliferation and induces apoptosis of human choriocarcinoma (BeWo) cells. Invention New Drugs (27): 236-252.

5. Nagini S, Bhuvaneswari V, Subapriya R (2005) Ethanolic neem leaf extract induces apoptosis in the hamster buccal pouch carcinogenesis model by modulation of BCL-2, BIM, caspase 8 and caspase 3 . Asian Pac J Cancer Prev 6(4): 515-520.
6. Veeraraghavan J, Aravindan S, Natarajan M, Awasthi V, Herman TS, et al. (2011) Neem leaf extract induces radio sensitization in human neuroblastoma xenograft through modulation of apoptotic pathway. Anticancer Res 31(1): 161-170.

7. Garofalo A, Goossens L, Six P, Lemoine A, Ravez S, et al. (2011) Impact of aryloxy-linked quinazolines: A novel series of selective VEGFR-2 receptor tyrosine kinase inhibitors. Bioorg Med Chem Lett (21): 21062112.

8. Deota PT, Upadhyay PR, Patel KB, Mehta KJ, Kamath BV, et al. (2007) Estimation and isolation of azadirichitin A from neem (Azadirachta indica) seed kernels using HPLC. Journal of Liquid Chromatography and Related Technology 23(14): 2225-2235.

9. Dhamija I, Kumar N, Manjula SN, Parihar V, Setty MM, et al. (2013) Preliminary evaluation of in vitro cytotoxicity and in vivo antitumor activity of premna herbacea roxb in ehrlich ascites carcinoma model and Daltons lymphoma ascites model. Experimental and Toxicological Pathology 65(3): 235-242.

10. Parameshwar R, Vamaraju HB, Paturi M, Narendra SC, Kolli S (2016) Design synthesis in silico toxicity prediction molecular docking and evaluation of novel pyrazole derivatives as potential antiproliferative agents. Excli Journal 15: 187-202.

11. Fatheya M, Hatem AEM (2014) Antitumor effect of azadirachta indica (neem) on murine solid ehrlich carcinoma. Academic Journal of Cancer Research 7(1): 38-45.

12. Roy MK, Kobori M, Takenaka M (2006) Inhibition of colon cancer (HT-29) cell proliferation by a triterpenoid isolated from Azadirachta indica is accompanied by cell cycle arrest and upregulation of p21, Planta Medica 72: 917-923.

13. Priyadarsini RV, Manikandan P, Kumar GH, Nagini S (2009) The neem limonoids azadirachtin and nimbolide inhibit hamster cheek pouch carcinogenesis by modulating xenobiotic-metabolizing enzymes, DNA damage, antioxidants, invasion, and angiogenesis. Free Radic Res 43: 492-504.

14. Tepsuwan A, Kupradinun P, Kusamaran WR (2002) Chemopreventive potential of neem flowers on carcinogenesis induced rat mammary and liver carcinogenesis. Asian Pac J Cancer Prev 3(3): 231-238. 
15. Paul R, Prasad M, Sah NK (2011) Anticancer biology of Azadirachta indica (neem), Cancer Biology. Therapy 12(6): 467-476.

This work is licensed under Creative Commons Attribution 4.0 License

DOI: 10.19080/CTBEB.2019.18.555997
16. Akihisa T (2011) Cytotoxic, and apoptosis- inducing activity of limonoids from the seeds of azadirachta indica (Neem). J Nat Prod (74): 866-870.

\section{Your next submission with Juniper Publishers will reach you the below assets}

- Quality Editorial service

- Swift Peer Review

- Reprints availability

- E-prints Service

- Manuscript Podcast for convenient understanding

- Global attainment for your research

- Manuscript accessibility in different formats ( Pdf, E-pub, Full Text, Audio)

- Unceasing customer service

Track the below URL for one-step submission https://juniperpublishers.com/online-submission.php 